\title{
Erratum to: Study on the properties of vacancies and phonon dispersions by the improved ones of the modified analytic embedded atom method potentials for $\mathrm{Al}, \mathrm{Ni}$, and $\mathrm{Ir}$
}

\author{
Hak-Son Jin ${ }^{1} \cdot$ Jae-Yon Pak ${ }^{1}$ - Yon-Song Jong ${ }^{1}$
}

Published online: 12 September 2017

(C) Springer-Verlag GmbH Germany 2017

Erratum to: Appl. Phys. A (2017) 123:257

DOI 10.1007/s00339-017-0872-y

The original version of this article unfortunately contained a mistake.

The legend of Fig. 1 was incorrect. The correct legend is given here.
Fig. 1 Pair potentials and their first and second derivatives as functions of the reduced distance $r / r l$ for FCC metals $\mathrm{Al}, \mathrm{Ni}$, and Ir (the unit of pair potential is $\mathrm{eV}$. The left column is the pair potentials, the middle column the first derivatives, and the right column the second derivatives)

The online version of the original article can be found under doi:10.1007/s00339-017-0872-y.

Hak-Son Jin

ryongnam3@yahoo.com

1 Kim Il Sung University, Pyongyang, Democratic People's

Republic of Korea 